\title{
A Comparison of $0.3 \%$ Topical Nifedipine Ointment vs Lateral Sphincterotomy in the Treatment of Chronic Anal Fissure
}

\author{
Pradyot Shahi ${ }^{1}$, Brijesh Sharma $^{2}$, Mahesh Solanki ${ }^{3}$
}

\begin{abstract}
Introduction: A chronic anal fissure is a common anorectal condition associated with high sphincter pressure and a reduction in mucosal blood flow, with secondary local ischemia and a poor healing tendency. The principle of treatment is breaking the cycle of pain, spasm, and ischemia thought to be responsible for the development of fissure in ano.

Aim: To assess and compare the topical application of $0.3 \%$ nifedipine and lateral internal sphincterotomy as treatment modalities in patients diagnosed with chronic anal fissure.

Materials and methods: This study was a prospective comparative study where 100 patients who presented in a surgical outpatient department of $\mathrm{MGMCH}$, Jaipur with complaints of the painful passage of stool, with or without bleeding of $>6$ weeks duration, diagnosed to be having chronic anal fissure, were randomly selected and classified into two groups, each consisting of 50 patients. The patients in the first group were subjected to pharmacological sphincterotomy using topical application of $0.3 \%$ nifedipine while patients in group II were subjected to lateral sphincterotomy. Outcomes in each group were followed up at $2,4,6,8$, and 12 weeks.

Results: In our study, fissures at 4, 6, 8, and 12 weeks were healed in 78, 86, 92, and 90\% patients, respectively, in the nifedipine ointment group whereas in the lateral sphincterotomy group fissures at 4, 6, 8 and 12 weeks had healed in $88,92,98$, and 98\% patients, respectively. Nineteen patients (38\%) developed side effects in the nifedipine group, compared with 10 patients $(20 \%)$ in the sphincterotomy group.

Conclusion: With good treatment outcome nifedipine ointment has the potential to become the first-line treatment for chronic anal fissures. It represents a new, promising, effective alternative to lateral internal sphincterotomy but in case pharmacological therapy fails, lateral sphincterotomy is the surgical option of choice.

Keywords: $0.3 \%$ Nifedipine ointment, Anal fissure, Lateral internal sphincterotomy.

Journal of Mahatma Gandhi University of Medical Sciences \& Technology (2020): 10.5005/jp-journals-10057-0135
\end{abstract}

\section{INTRODUCTION}

Anorectal disorders include a diverse group of pathological disorders that generate significant patient discomfort. ${ }^{1}$ A common complaint with which the patients present is an anal fissure which is a tear in the anal mucosa extending from the anal verge toward the dentate line. It is common in young adults. Epidemiological studies show no gender predominance. Anal fissure occurs predominantly in the midline, most commonly posterior (90\%) with $10 \%$ anterior. $^{2}$

Typically, symptoms are severe pain during and after defecation and bright red rectal bleeding.

As the fissure becomes chronic, the bleeding may stop, although the pain will persist. A minority complain of pruritus, swelling, prolapse, and discharge. ${ }^{3}$

Most anal fissures are acute and resolve spontaneously or with conservative medical management in 10-14 days. It takes 6-8 weeks for the actual tear to heal. Chronicity is defined by both chronology and morphology. The chronological definition is rather loose, but most surgeons regard persistence beyond 6 weeks as a reasonable point when an acute fissure, now unlikely to heal with conservative treatment, may be considered chronic. ${ }^{4}$

Current evidence suggests that anal fissure is due to high sphincter pressure and secondary local ischemia. ${ }^{5}$ Chronic anal fissure is associated with hypertonia of the anal canal and a reduction in mucosal blood flow, with microcirculatory disturbances and a poor healing tendency.

The principle of treatment is breaking the cycle of pain, spasm, and ischemia thought to be responsible for the development of fissure in ano. First-line therapy to minimize anal trauma includes bulk agents, stool softeners, and warm sitz baths. ${ }^{6}$
${ }^{1}$ Department of General Surgery, Indira Gandhi Institute of Medical Sciences, Patna, Bihar, India

${ }^{2,3}$ Department of General Surgery, Mahatma Gandhi Medical College and Hospital, Jaipur, Rajasthan, India

Corresponding Author: Pradyot Shahi, Department of General Surgery, Indira Gandhi Institute of Medical Sciences, Patna, Bihar, India, Phone: +91 9973155135, e-mail: pradyot.shahi@gmail.com

How to cite this article: Shahi P, Sharma B, Solanki M. A Comparison of $0.3 \%$ Topical Nifedipine Ointment vs Lateral Sphincterotomy in the Treatment of Chronic Anal Fissure. J Mahatma Gandhi Univ Med Sci Tech 2020;5(3):77-82.

Source of support: Nil

Conflict of interest: None

Surgical treatment is widely recommended for chronic anal fissure and lateral internal anal sphincterotomy is the surgery most commonly performed. This procedure aims to decrease the spasm of the internal sphincter by dividing a portion of the muscle. Approximately $30 \%$ of the internal sphincter fibers are divided laterally by using either an open or closed technique. However, the incidence of incontinence to feces or flatus after this procedure ranges from 0 to $35 \%{ }^{6}$ To prevent permanent defects and subsequent disturbances of continence pharmacological manipulation in form of topical therapy of anal fissure that decreases tone of the internal anal sphincter and causes internal anal sphincter relaxation has gained popularity. It may be performed with botulinum toxin injections or the topical application of ointments, such as, calcium blockers (nifedipine or diltiazem), 
nitric oxide donors (glyceryl trinitrate), a potassium channel agonist (minoxidil), inhibitors of angiotensin-converting enzyme, phosphodiesterase inhibitors, cholinomimetic (bethanechol), and an alpha-adrenoreceptor antagonist (indoramin). ${ }^{7}$

The present study aims to compare the topical application of $0.3 \%$ nifedipine and lateral sphincterotomy as treatment modalities for chronic anal fissure in terms of their efficacy and adverse effects.

\section{A IM}

To assess and compare the topical application of $0.3 \%$ nifedipine and lateral internal sphincterotomy as treatment modalities in patients diagnosed with chronic anal fissure.

\section{Objectives}

- To assess and compare the efficacy and adverse effects of topical application of $0.3 \%$ nifedipine with that of lateral internal sphincterotomy in patients diagnosed with chronic anal fissure.

- To compare the complications associated with both the modalities of treatment.

- To decide on the better treatment for chronic anal fissure based on the findings of the study.

\section{Materials and Methods}

Type of study: Prospective comparative study. Period of study: January 2017 to September 2018.

Place of study: Mahatma Gandhi Medical College and Hospital, Jaipur.

Institute Ethics Committee approval was obtained before the start of the study.

Written and informed consent was obtained from all participants before enrolment into the study.

Sample size: 100 .

This study included 100 patients who presented with chronic anal fissure. These patients were randomly selected and classified into two groups, each consisting of 50 patients.

- Group I: 50 patients who were subjected to pharmacological sphincterotomy using topical application of $0.3 \%$ nifedipine.

- Group II: 50 patients who were subjected to lateral sphincterotomy.

Inclusion criteria for the study were:

All patients who presented in the surgical outpatient department with complaints of the painful passage of stool, with or without bleeding of $>6$ weeks duration, diagnosed to be having chronic anal fissure based on the history and clinical examination.

Exclusion criteria for the study were:

- Patient with currently active tuberculosis.

- History of hemorrhoids.

- Anorectal abscesses.

- Anal malignancies.

- Immunocompromised patients.

- Previous history of fecal incontinence or anal stenosis.

- Patients who have undergone previous anal surgeries.

- Patients with a history of bleeding diathesis.
The patients fulfilling the selection criteria were randomly divided into two equal groups by allocating the paper chit method. One group (group I) was treated with topical application of $0.3 \%$ nifedipine ointment thrice a day, for a period of 8 weeks and the other group (group II) was treated with lateral sphincterotomy.

The patients in group I were taught how to apply $0.3 \%$ nifedipine ointment locally at the site of the anal fissure and around the anal opening. The patients were asked to wash their hands before and after the procedure.

For patients in group II, basic routine investigations like complete blood counts, renal function tests, and ECG, chest X-ray was performed. Preanesthesia check was cleared and patients were planned for surgery. Fasting past midnight before surgery and IV antibiotics (ceftriaxone $1 \mathrm{~g} \mathrm{IV}$ ) was administered before the procedure.

\section{Follow-up}

Patients were followed up at 2, 4, 6, 8, and 12 weeks and were evaluated according to the planned parameters. A high fiber diet was encouraged. During each visit, inquiries were made regarding the expected complications like pain, bleeding, headache, flushing, anal irritation, and incontinence using a simple questionnaire. Fissures were examined for healing at 4,6, 8, and 12 weeks. Results of the follow-up were tabulated and analyzed.

\section{Data Collection and Analysis}

The collected data were analyzed with IBM (SPSS statistics software 23.0 Version). To describe the data descriptive statistics frequency analysis, percentage analysis was used for categorical variables and the mean and standard deviation (SD) were used for continuous variables.

\section{Results}

Although patients of all age groups were included in the study, the mean age of the nifedipine ointment group was 38.66 years, and that of the lateral sphincterotomy group was 37.24 years ( $p$ $=0.597)$. The number of males with fissures was almost double the number of females. A total of 67 males and 33 females were included in this study.

The patients had a mean duration of symptoms of 12.02 weeks in the nifedipine group with a minimum duration of 6 weeks and a maximum duration of 24 weeks. 11.36 weeks was the mean duration in the lateral sphincterotomy group with a minimum duration of 6 weeks and a maximum duration of 24 weeks. The mean duration was statistically comparable between the two groups $(p=0.432)$.

Eighty-six out of $100(86 \%)$ patients presented with posterior fissures and 14 had anterior fissures. In the nifedipine ointment group, 43 patients (86\%) had posterior fissures and in the lateral sphincterotomy group as well 43 patients (86\%) had posterior fissures. The groups were not statistically different in the distribution of the location of the fissure $(p=1)$.

Perianal pain was the most common presenting symptom in our patients and was present in 83 out of 100 patients (83\%). Forty-one patients in group I (82\%) and 42 patients in group II presented with perianal pain $(p=0.790)$. The groups were compared statistically.

Bleeding per rectum was present in 68 out of 100 patients $(68 \%)$ and 69 out of 100 patients (69\%) had complaints of pruritus ani. 


\section{Postoperative Outcome}

\section{Healing at 4 Weeks}

Thirty-nine out of 50 patients (78\%) who were treated with nifedipine ointment showed features of healing at 4 weeks of treatment. In the lateral sphincterotomy group, 44 out of 50 patients (88\%) showed features of healing at the end of 4 weeks. The groups were found to be statistically comparable in this regard $(p=0.183)$ (Table 1).

\section{Healing at 6 Weeks}

At 6 weeks, 43 out of 50 patients (86\%) in group I and 46 out of 50 (92\%) patients in group II showed features of healing. The groups were statistically comparable $(p=0.525)$ (Table 2$)$.

\section{Healing at 8 Weeks}

At the end of 8 weeks, $92 \%$ of patients in the nifedipine group had healed in comparison to $98 \%$ of patients in the lateral sphincterotomy group. With a $p$ value of 0.362 , the groups were comparable (Table 3).

\section{Healing at 12 Weeks}

At follow-up at the end of 12 weeks, 45 out of 50 patients (90\%) in the nifedipine group had healed completely as opposed to 49 out of 50 patients (98\%) in the lateral sphincterotomy group. The groups were found to be comparable on statistical analysis in this regard $(p=0.204)$ (Table 4$)$.

\section{Adverse Effects and Complications Headache}

Of the 50 patients who were treated with nifedipine ointment, 6 patients (12\%) developed a headache. The headache was not severe. There was no incidence of headache in the lateral sphincterotomy group. In comparison, the incidence of headache in patients treated with nifedipine ointment is statistically significant with a $p$ value of 0.027 (Table 5).

\section{Flushing}

In the nifedipine ointment group, 5 out of 50 (10\%) patients developed flushing. There was no flushing seen in the lateral sphincterotomy group. The groups were found statistically comparable in this regard $(p=0.056)$ (Table 6).

\section{Anal Irritation}

Anal irritation was seen in 8 out of 50 patients (16\%) in group I and in 3 out of 50 patients (6\%) in group II. The groups were statistically comparable $(p=0.200)$ (Table 7).

\section{Minor Incontinence}

No patients in the nifedipine group had a problem with incontinence. Four out of 50 patients (8\%) in the lateral sphincterotomy group had minor incontinence to flatus. The groups were statistically comparable $(p=0.117)$ (Table 8$)$

Table 1: Healing at 4 weeks

\begin{tabular}{llllll}
\hline & & & \multicolumn{2}{c}{ Groups } \\
\cline { 4 - 5 } & & & Group I & Group II & Total \\
\hline Healing at 4 weeks & No & Count & 11 & 6 & 17 \\
& & $\%$ & 22.0 & 12.0 & 17.0 \\
& Yes & Count & 39 & 44 & 83 \\
Total & & Count & 78.0 & 58.0 & 83.0 \\
& & \% within groups & 100.0 & 50 & 100 \\
\hline
\end{tabular}

Table 2: Healing at 6 weeks

\begin{tabular}{|c|c|c|c|c|c|}
\hline & & & \multicolumn{2}{|c|}{ Groups } & \multirow[b]{2}{*}{ Total } \\
\hline & & & Group I & Group II & \\
\hline \multirow[t]{4}{*}{ Healing at 6 weeks } & No & Count & 7 & 4 & 11 \\
\hline & & $\%$ & 14.0 & 8.0 & 11.0 \\
\hline & Yes & Count & 43 & 46 & 89 \\
\hline & & $\%$ & 86.0 & 92.0 & 89.0 \\
\hline \multirow[t]{2}{*}{ Total } & & Count & 50 & 50 & 100 \\
\hline & & $\%$ within groups & 100.0 & 100.0 & 100.0 \\
\hline
\end{tabular}

Table 3: Healing at 8 weeks

\begin{tabular}{llllcc}
\hline & & & \multicolumn{2}{c}{ Groups } \\
\cline { 3 - 5 } & & & Group I & Group II & \multicolumn{1}{c}{ Total } \\
\hline Healing at 8 weeks & No & Count & 4 & 1 & 5 \\
& & $\%$ & 8.0 & 2.0 & 5.0 \\
& Yes & Count & 46 & 49 & 95 \\
Total & & Count & 92.0 & 98.0 & 95.0 \\
& & \% within groups & 100.0 & 50 & 100 \\
\hline
\end{tabular}


Table 4: Healing at 12 weeks

\begin{tabular}{|c|c|c|c|c|c|}
\hline & & & \multicolumn{2}{|c|}{ Groups } & \multirow[b]{2}{*}{ Total } \\
\hline & & & Group I & Group II & \\
\hline \multirow[t]{4}{*}{ Healing at 12 weeks } & No & Count & 5 & 1 & 6 \\
\hline & & $\%$ & 10.0 & 2.0 & 6.0 \\
\hline & Yes & Count & 45 & 49 & 94 \\
\hline & & $\%$ & 90.0 & 98.0 & 94.0 \\
\hline \multirow[t]{2}{*}{ Total } & & Count & 50 & 50 & 100 \\
\hline & & $\%$ within groups & 100.0 & 100.0 & 100.0 \\
\hline
\end{tabular}

Table 5: Headache

\begin{tabular}{lllccc}
\hline & & \multicolumn{2}{c}{ Groups } \\
\cline { 3 - 5 } & & & Group I & Group II & Total \\
\hline Headache & No & Count & 44 & 50 & 94 \\
& & $\%$ & 88.0 & 100.0 & 94.0 \\
& Yes & Count & 6 & 0 & 6 \\
Total & & $\%$ & 12.0 & 0.0 & 6.0 \\
& & Count & 50 & 50 & 100 \\
\hline
\end{tabular}

Table 6: Flushing

\begin{tabular}{lllccc}
\hline & & \multicolumn{2}{c}{ Groups } \\
\cline { 3 - 5 } & & & Group I & Group II & Total \\
\hline Flushing & No & Count & 45 & 50 & 95 \\
& & $\%$ & 90.0 & 100.0 & 95.0 \\
& Yes & Count & 5 & 0 & 5 \\
Total & & $\%$ & 10.0 & 0.0 & 5.0 \\
& & Count & 50 & 50 & 100 \\
\hline
\end{tabular}

Table 7: Anal irritation

\begin{tabular}{lllccc}
\hline & & & \multicolumn{2}{c}{ Groups } \\
\cline { 4 - 5 } & & & Group I & Group II & Total \\
\hline Anal irritation & No & Count & 42 & 47 & 89 \\
& & $\%$ & 84.0 & 94.0 & 89.0 \\
& Yes & Count & 8 & 3 & 11 \\
Total & & $\%$ & 16.0 & 6.0 & 11.0 \\
& & Count & 50 & 50 & 100 \\
\hline
\end{tabular}

Table 8: Minor incontinence

\begin{tabular}{lllccc}
\hline & & \multicolumn{3}{c}{ Groups } \\
\cline { 4 - 6 } & & & Group I & Group II & Total \\
\hline Minor incontinence & No & Count & 50 & 46 & 96 \\
& & $\%$ & 100.0 & 92.0 & 96.0 \\
& Yes & Count & 0 & 4 & 4 \\
Total & & $\%$ & 0.0 & 8.0 & 4.0 \\
& & Count & 50 & 50 & 100 \\
\hline
\end{tabular}




\section{Discussion}

In this study, we have compared a promising method of pharmacological sphincterotomy, i.e., topical application $0.3 \%$ nifedipine ointment with the gold standard of surgical management, i.e., lateral sphincterotomy.

The demographic profile of the patients in the two groups was comparable. The mean age of the patients in the nifedipine group was 38.66 and 37.24 years in the lateral sphincterotomy group. This was comparable to the mean age of patients in the studies by Jensen et al. ${ }^{8}$ and Katsinelos et al. ${ }^{9}$

The patients in our study were predominantly male in the two groups with an overall male: female ratio of 67:33. This was found to be higher compared to the studies undertaken by Jensen et al., Motie and Hashemi, ${ }^{10}$ and Katsinelos et al. ${ }^{9}$

In our study, $14 \%$ of patients had anterior fissures, while $86 \%$ had posterior fissures. This is comparable to studies undertaken by Katsinelos et al. ${ }^{9}$ which had $83.9 \%$ of patients with posterior fissure and a review by Altomare et al. ${ }^{11}$ which showed that 80 to $90 \%$ of patients have posterior fissures.

The patients in our study presented with a mean symptom duration of 12.02 weeks in the nifedipine group and 11.36 weeks in the lateral sphincterotomy group. Among the studies which discussed the duration of symptoms, our results were lower compared to observations of Jensen et al. ${ }^{8}$ who reported a mean symptom duration of 9 months, and Katsinelos et al. ${ }^{9}$ who reported a mean symptom duration of 4 months.

The patients in our study presented most commonly with pain in the perianal region (83\%), followed by complaints of pruritus ani (69\%) and bleeding per rectum (68\%). This was found consistent with the observations of published literature and texts. ${ }^{12}$

In our study, fissures at 4,6, 8, and 12 weeks were healed in 78, 86,92 , and $90 \%$ patients, respectively, in the nifedipine ointment group as shown in Figure 1. One patient showed a recurrence of a fissure at 12 weeks. These findings were consistent with earlier studies by Golfam et al. ${ }^{13}$ which showed complete healing of fissure in $70 \%$ of cases after 4 weeks of treatment with nifedipine ointment. Katsinelos et al. ${ }^{9}$ published that complete healing of fissure at 8 weeks was observed in $96.7 \%$ of patients after treatment with topical nifedipine and at long-term follow-up of 19 months the overall healing rate was $93 \%$. In the study by Perrotti et al., ${ }^{14} 94.5 \%$ of fissures had healed at 6 weeks of treatment with topical nifedipine.

In the lateral sphincterotomy group, fissures at 4, 6, 8, and 12 weeks had healed in $88,92,98$, and $98 \%$ of patients, respectively (Fig. 1). No recurrence was seen at 12 weeks. Studies by Ram et al. ${ }^{15}$ and Katsinelos et al. ${ }^{9}$ show similar rates of healing.

Out of the 50 patients treated with topical application of $0.3 \%$ nifedipine ointment, six patients (12\%) had a mild headache, five patients (10\%) had flushing, and eight patients (16\%) had anal irritation. None of the side effects were severe enough to affect treatment. In the lateral sphincterotomy group, 3 out of 50 patients (6\%) had anal irritation and 4 patients (8\%) had minor incontinence only to flatus. Only the occurrence of mild headache was statistically significant between both groups.

The side effect profile is comparable to a study by Katsinelos et al. ${ }^{9}$ in which headache was seen in $15.6 \%$ of patients treated with topical nifedipine ointment, flushing also in $15.6 \%$ of patients, and anal irritation in $18.7 \%$ of patients. In their study, the patients treated with lateral sphincterotomy exhibited anal irritation in $6.2 \%$ of cases and minor incontinence in $12.5 \%$ of cases. Golfam et al. ${ }^{13}$ had $6.6 \%$ of patients complain of minor headache on treatment with topical nifedipine.

The minor incontinence noted in a few patients is comparable to earlier studies by Ram et al. ${ }^{15}$ and Weaver et al. ${ }^{16}$

Patients in our study were evaluated in the follow-up period and healing of fissure was recorded at the end of 4, 6, 8, and 12 weeks. The outcome was comparable between the two groups. Katsinelos et al. ${ }^{9}$ published similar results where they showed that topical nifedipine ointment represents a new, promising, easily handled, and effective alternative to lateral internal sphincterotomy

\section{Conclusion}

There have been many changes in the treatment of anal fissure since the last decade. Medical treatment, being non-invasive is presumed as the first option but surgical sphincterotomy remains the gold standard for the treatment of chronic anal fissure.

The healing rates shown by topical application of $0.3 \%$ nifedipine ointment were statistically compared with those shown by lateral sphincterotomy.

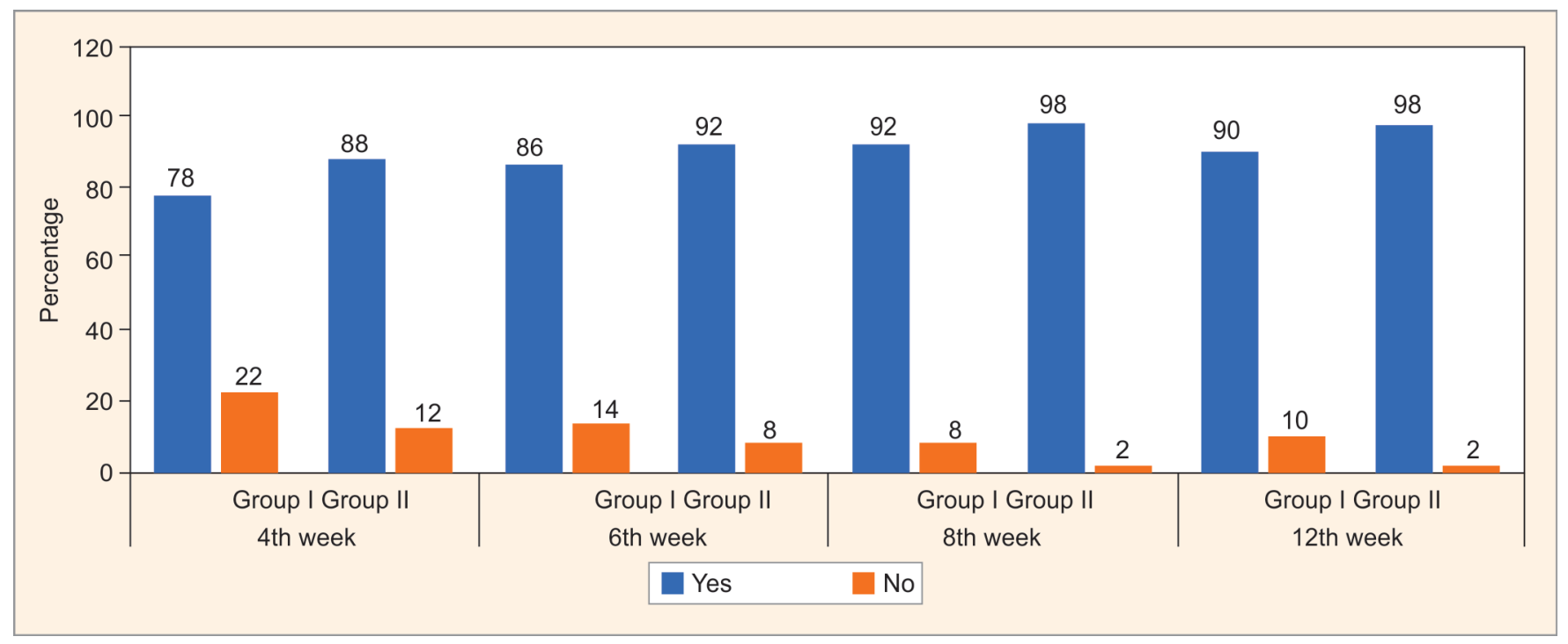

Fig. 1: Comparison of healing at 4, 6, 8, and 12 weeks 
With good treatment outcome, nifedipine ointment has the potential to become the first-line treatment for chronic anal fissures. Should pharmacological therapy fail, lateral sphincterotomy is the surgical option of choice.

Although this study gives encouraging results for using topical $0.3 \%$ nifedipine ointment as first-line treatment for chronic anal fissures, we suggest more evaluation in further studies over a larger number of patients with longer-term follow-up to establish this treatment modality.

\section{References}

1. Gupta PJ. A review of ano-rectal disorders and their treatment. Bratisl Lek Listy 2006;107(8):323-331.

2. Kodner IJ, Fry RD, Fleshman JW, et al. Colon rectum and anus. In: Schwartz's Principles of Surgery. 7th ed., USA: McGraw Hill Health Professions Division; 1999. p. 1265.

3. Gordan PH. Fissure in ano. In: Gordon PH, Nivatvongs S, ed. Principles and Practice of Surgery for the Colon, Rectum and Anus. 2nd ed., St Louis: Quality Medical Publishing; 1999. pp. 217-240.

4. Rosai J. In: Rosai and Ackerman's Surgical Pathology. 9th ed., St Louis: Elsevier; 2004. p. 858.

5. Gibbons CP, Read NW. Anal hypertonia in fissures: cause or effect? $\mathrm{Br}$ J Surg 1986;73(6):443-445. DOI: 10.1002/bjs.1800730609.

6. Bullard KM, Rothenberger DA. Colon, rectum and anus. Shwartz's Princip Surg 2005;8:28-1104.

7. Madalinski M, Kalinowski L. Novel options for the pharmacological treatment of chronic anal fissure - role of botulin toxin. Curr Clin Pharmacol 2009;4(1):47-52. DOI: 10.2174/157488409787236083.

8. Jensen SL, Lund F, Nielsen OV, et al. Lateral subcutaneous sphincterotomy versus anal dilatation in the treatment of fissure in ano in outpatients: a prospective randomised study. Br Med J (Clin Res Ed) 1984;289(6444):528-530. DOI: 10.1136/bmj.289.6444.528.

9. Katsinelos P, Papaziogas B, Koutelidakis I, et al. Topical $0.5 \%$ nifedipine vs. lateral internal sphincterotomy for the treatment of chronic anal fissure: long-term follow-up. Int J Colorectal Dis 2006;21(2):179-183. DOI: 10.1007/s00384-005-0766-x.

10. Motie MR, Hashemi P. Chronic anal fissure: a comparative study of medical treatment versus surgical sphincterotomy. Acta Med Iran 2016;54(7):437-440.

11. Altomare DF, Binda GA, Canuti S, et al. The management of patients with primary chronic anal fissure: a position paper. Tech Coloproctol 2011;15(2):135. DOI: 10.1007/s10151-011-0683-7.

12. Sarhan $\mathrm{H}$. Closed versus open lateral internal sphincterotomy in treatment of chronic anal fissure: a comparative study. Arch Clin Exp Surg 2012;2012(1):219-223. DOI: 10.5455/aces.20120522101831.

13. Golfam F, Golfam P, Golfam B, et al. Comparison of topical nifedipine with oral nifedipine for treatment of anal fissure: a randomized controlled trial. Iran Red Crescent Med J 2014;16(8):e13592. DOI: 10.5812/ircmj.13592.

14. Perrotti P, Bove A, Antropoli C, et al. Topical nifedipine with lidocaine ointment vs. active control for treatment of chronic anal fissure. Dis Colon Rectum 2002;45(11):1468-1475. DOI: 10.1007/s10350-004-64521.

15. Ram E, Vishne T, Lerner I, et al. Anal dilatation versus left lateral sphincterotomy for chronic anal fissure: a prospective randomized study. Tech Coloproctol 2007;10:300-301. DOI: 10.1007/s10151-0070373-7.

16. Weaver RM, Ambrose NS, Alexander-Williams J, et al. Manual dilatation of anus vs. Lateral subcutaneous sphincterotomy in the treatment of chronic fissure-in-ano. Results of a prospective, randomized, clinical trial. Dis Colon Rectum 1987;30(6):420-423. DOI: 10.1007/BF02556488. 